\title{
Stress Analysis and Model Test of Rock Breaking by Arc Blade Wedged Hob
}

\author{
Ying-chao Liu ${ }^{1}$, Bo Liu ${ }^{1}$, Yu-sheng Jiang ${ }^{1}$ and Chi Zhang ${ }^{2}$ \\ ${ }^{1}$ School of Mechanics and Civil Engineering, China University of Mining and Technology-Beijing, Beijing 100083, China \\ ${ }^{2}$ Beijing Fengtai Municipal Commission of Housing and Urban-rural Development, Beijing, 100036, China
}

Received 8 May 2015; Accepted 9 December 2015

\begin{abstract}
Based on rock compression-shear damage theory, the mechanical characteristics of an arc blade wedged hob were analyzed to study the rock fragmentation mechanism of hob during excavation, and rock fragmentation forecasting model of the arc blade wedged hob was improved. A spoke type cutter model which is similar to the tunnel boring machine (TBM) cutter head was designed to study the rock fragmentation efficiency in different cutter spacing by adjusting the bearing sleeve size to obtain different distances between the hobs. The results show that the hob-breaking rock force mainly comes from three directions. The vertical force along the direction of the tunnel excavation, which is associated with uniaxial compressive strength of rock mass, plays a key role in the process of rock fragmentation. Field project data shows that the prediction model's results of rock fragmentation in this paper are closer to the measured results than the results of the traditional linear cutting model. The optimal cutter spacing exists among different cutter spacings to get higher rock fragmentation rate and lower energy consumption during rock fragmentation. It is of great reference significance to design the arc blade wedged hob and enhance the efficiency of rock fragmentation in rock strata.
\end{abstract}

Keywords: TBM, Arc Blade Wedged Hob, Penetration Depth, Model Test, Cutter Spacing.

\section{Introduction}

Tunnels are excavated by TBM cutter rolling and compacting rock. A key component in the successful planning of TBM tunneling is the efficiency of the disc cutter breaking rock. Theoretical analysis and experimental research on the vertical thrust prediction model of a disc cutter breaking rock began in the 1960s. Evans (1966) suggested that the vertical thrust of a sharp edge cutter breaking rock is proportional to the projection area of the rock surface, and the rock is only broken by extrusion. Roxborough [1] also adopted Evans's argument about the calculation of vertical thrust, but with a rectangular crosssectional area. Levent Ozdemir et al. [2] proposed two types of disc cutter force prediction formulas, including the linear cutting model, the CSM model. Some scholars conducted a large number of practical engineering field observations and data collection. Gong Q. M. et al. [3], [4], [5] did laboratory model tests to simulate rock breaking. The corresponding experimental formula is founded. On the other hand, [6] based on the particle discrete element method, numerical simulation models of rock breaking are established to study the mechanism of cutter breaking rock. Hassanpour J. et al. [7] analysed the TBM performance in relation to the Field Penetration Index. Sapigni et al. [8] and Ribacchi et al. [9] analyzed the relationship between TBM performance and RMR.

All in all, it is necessary to give more research on the

\footnotetext{
* E-mail address: liuyingcha0111@163.com ISSN: 1791-2377 @ 2015 Kavala Institute of Technology. All rights reserved.
}

development of the new models due to the existence of some shortcomings in the prediction models and the growth of TBM manufacturing technology. In this paper, a vertical cutting force prediction model of arc blade wedged hob breaking rock is improved, and is verified by the project data in Nanjing. A spoke type cutter model similar to the tunnel boring machine (TBM) cutter head is designed to study rock fragmentation efficiency of different cutter spacing by adjusting the bearing sleeve size in different distances among the hobs.

\section{Description of the problem}

During the excavating part of TBM, hobs driven by cutters have an extrusion effect on rock. When the pressure exceeds the uniaxial compressive strength, the rock beneath the blade is crushed and then the hob will penetrate into the rock. Driven by the cutter's rolling torque, the hob will form a series of concentric grooves on the rock surface. With continuing pressure, the blade penetrates into the rock further. Cracks appear and spread deeply with the increasing of the hob penetration depth. When the force exceeds the shear and tensile strength of the rock, the cracks in the rock between the adjacent hobs gradually interconnect. Rock fragments drop due to the extrusion and roll of the hob. Finally, rock-breaking by cutter is finished.

The disc cutter cross-section type can be divided into three categories: sharp blade wedged section, arc blade wedged section, and approximate constant cross-section. Most prediction models analyse hobs with sharp blade wedged section and approximate constant cross-section. The rock breaking mechanism is only assumed as crush failure or 
shear failure, it does not match with the actual rock breaking form in practice. As a result, there is a gap between the rockbreaking force of prediction models and engineering data.

For rock with relatively low strength, rock-breaking efficiency of arc blade wedged hob is higher during excavation. Based on rock-breaking mechanism and rock failure law, a vertical cutting force prediction model of arc blade wedged hob breaking rock is proposed, and is verified by engineering data. Model tests are carried out in the laboratory to study the rock-breaking law of hobs.

\section{Methodology}

\subsection{Stress analysis of arc blade wedged hob}

In the following analysis of rock breaking, rock fragments are divided into extruded fragments and sheared fragments. In Figure 1, region 1 is the nucleus formed by extruded fragments under the hob blade, it is extrusion failure block. Region 2 shows the sheared fragments resulting from the lateral force of the hob blade, it is shear failure block.

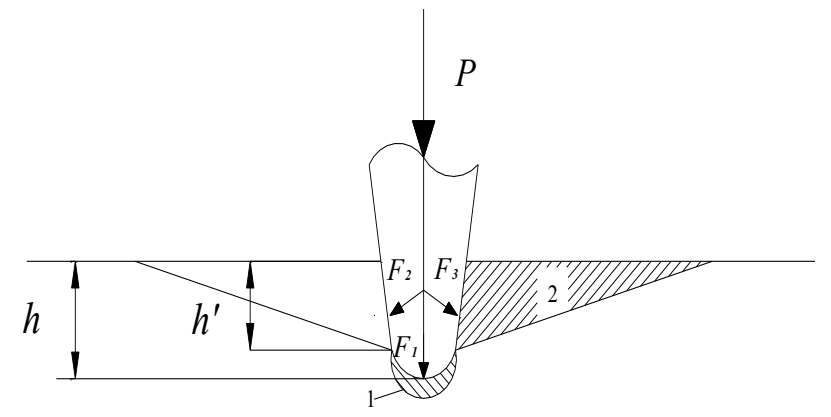

Fig. 1. Rock failure mode by arc blade wedged hob.

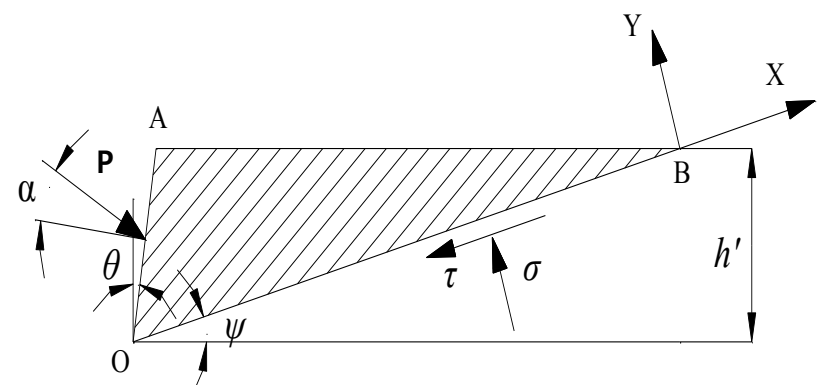

Fig.2. Stress analysis of shear failure block

Figure 2 shows the stress analysis of sheared fragments in the process of arc blade wedged hob breaking rock, where $\theta$ is half the angle of hob blade and $h^{\prime}$ is the thickness of sheared fragments in the vertical direction. The OA plane is the contact surface between the hob's arc blade and rock, where normal stress and frictional force are distributed. Assuming $\alpha$ is the frictional angle between the hob and rock, the normal stress on the contact surface is uniform, and the resulting force generated by the hob on the rock is P. $\psi$ is the angle between the failure surface under shear effect and horizontal plane, which relates to the fracture angle of the rock. The OB plane is the failure surface under shear crushing, which follows the Mohr-Coulomb failure criterion. The relationship between $\tau$ and $\sigma$ is:

$$
\tau=c+\sigma \tan \varphi_{b}
$$

Where: $\tau=$ Shear stress on shear failure surface; $\sigma=$ Normal stress on shear failure surface; $\varphi_{b}=$ The internal friction angle of rock; $c=$ The cohesion of rock.

In the process of rock fragmentation, friction angle, cohesion, fracture angle, and friction coefficient with the hob are the parameters related to the physical and mechanical properties of the rock. Based on the stress analysis of shear failure block, $\mathrm{X}, \mathrm{Y}$ direction of the balanced force can be found:

$$
\begin{aligned}
& \sum X=0, \frac{h^{\prime}}{\cos \theta} P \sin \left(\frac{\pi}{2}-\theta-\alpha-\psi\right)-\frac{h^{\prime} \tau}{\cos \left(\frac{\pi}{2}-\psi\right)}=0 \\
& \sum Y=0, \frac{h^{\prime}}{\cos \left(\frac{\pi}{2}-\psi\right)} \sigma-\frac{h^{\prime}}{\cos \theta} P \cos \left(\frac{\pi}{2}-\theta-\alpha-\psi\right)=0
\end{aligned}
$$

By the formula (1)-(3), P can be obtained:

$$
P=\frac{c \cdot \cos \varphi_{b} \cdot \cos \theta}{\cos \left(\theta+\varphi_{b}+\alpha+\psi\right) \cdot \sin \psi}
$$

Formula (4) is the force calculation of shear failure block. When $\theta+\varphi_{b}+\alpha+\psi \geq \pi / 2, P$ is negative or tends to $\infty$, i.e., $\theta \geq \pi / 2-\left(\varphi_{b}+\alpha+\psi\right)$. Because of the larger cutter blade angle, both sides of the blade do not touch the rock, and the rock will not experience shear failure and the rockbreaking efficiency of the hob is in the vertical extrusion. $\theta^{\prime}=\pi / 2-\left(\varphi_{b}+\alpha+\psi\right), \theta^{\prime}$ is the critical angle when rock appears shear failure.

Based on reasonable mechanical simplification, the arc is divided into shear and extrusion sections, and the two area demarcation principles is proposed. The arc blade structure is shown in Figure 3, where the CDE segment is the arc blade part. Through analysis of formula (4), there are two points $\mathrm{O}$ and $\mathrm{F}$, which are demarcation point under different forces including the OF section of extrusion failure, OC and FE section of shear failure. The relationship between the cutting depth and the height of shear failure is:

$h^{\prime}=h-r\left(1-\cos \theta^{\prime}\right)$

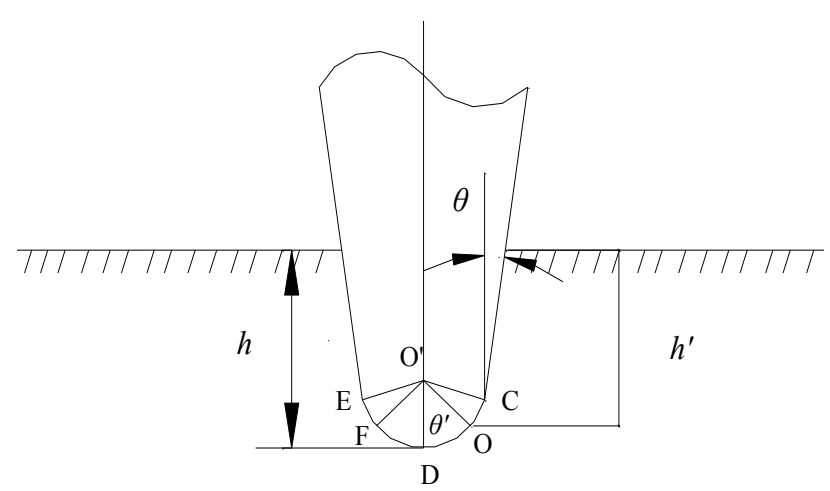

Fig. 3. Hob arc demarcation point of rock breaking. 


\subsection{Vertical cutting force prediction model of arc blade wedged hob}

There are three kinds of force in the process of rock breaking during excavation, including arc blade tip extrusion force and two side edged force. It is vertical force along the direction of tunnel excavation that plays a key role in the process of rock fragmentation. The vertical direction force $F_{v}$ is the sum of $F_{v 1}, F_{v 2}$, and $F_{v 3}$, which are the vertical component of force $F_{1}, F_{2}$, and $F_{3}$, respectively. The vertical cutting force prediction model of an arc blade wedged hob can be found by calculating the forces in the three directions.

\subsubsection{Calculation of $F_{v 1}$}

$F_{v l}$ is the vertical component of force applied to the hob in extrusion area. Because of the rock compression failure, the strength in the rock reaches uniaxial compressive strength. $F_{v l}$ is calculated as:

$$
F_{v 1}=A \sigma_{c}
$$

Where: $A=$ extrusion rock breaking area; $\sigma_{c}=$ uniaxial compressive strength of rock.

Formula (6) shows that $F_{v l}$ is extrusion rock breaking area in the vertical direction projection plus rock uniaxial compressive strength. The projection area is simplified as a triangle (the simplified area is considered feasible by the CSM model) (Ozdemir L.et al. 1977) as is shown in Figure 4.

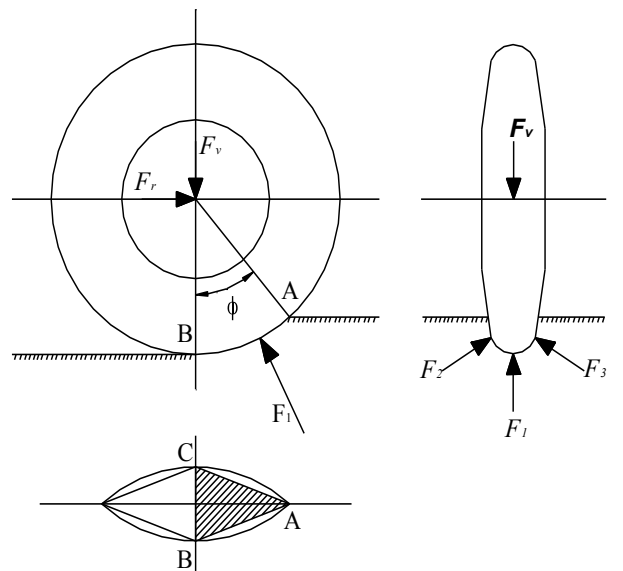

Fig. 4. Stress analysis of arc blade wedged hob. (Ozdemir. L.1977)

Based on the shape characteristics of the arc blade wedged hob and penetration depth, $F_{v l}$ is calculated under two conditions: (1) when the hob penetration depth $h \leq r\left(1-\cos \theta^{\prime}\right)$, the projection area is a function of penetration depth $h$ and the projection area rises with the increase of penetration depth $h, B C=2 \sqrt{2 r h-h^{2}}$, then:

$F_{v 1}=S_{A B C} \cdot \sigma_{c}=R \sin \phi \cdot \sqrt{2 r h-h^{2}} \cdot \sigma_{c}$

(2) When the hob penetration depth $h>r\left(1-\cos \theta^{\prime}\right)$,

$B C=2 r \sin \theta^{\prime}$, the projection area is fixed, then

$F_{v 1}=S_{A B C} \cdot \sigma_{c}=R \sin \phi \cdot r \sin \theta^{\prime} \cdot \sigma_{c}$

Where: $R=$ cutter radius;

$\theta^{\prime}=$ crushing critical angle;

$r=$ radius of hob's arc;

$$
\phi=\text { contact angle of hob and rock, } \phi=\arccos \frac{R-h}{R}
$$

3.2.2 Calculation of $\boldsymbol{F}_{v 2}, \boldsymbol{F}_{\boldsymbol{v} 3}$

The magnitude of force $F_{v 2}$ and $F_{v 3}$ is also influenced by penetration depth. When the penetration depth $h \leq r\left(1-\cos \theta^{\prime}\right)$, the rock is squeezed, but the shear stress is 0 , then $F_{v 2}=F_{v 3}=0$. When the depth of penetration depth $h>r\left(1-\cos \theta^{\prime}\right)$, the hob blade will have a shear effect on the rock, and the rock experiences shear fracture at this time. $F_{v 2}=F_{v 3}>0$

$$
F_{v 2}=F_{v 3}=F_{2} \cos \left(\frac{\pi}{2}-\theta-\alpha\right)=P \frac{S_{O A B}}{\cos \theta} \sin (\theta+\alpha)
$$

Where: $\theta=$ half angle of cutter blade;

$\alpha=$ friction angle between rock and hob;

$\mathrm{S}_{\mathrm{OAB}}=$ projection area in the vertical direction between shear breaking block contacting with hob blade.

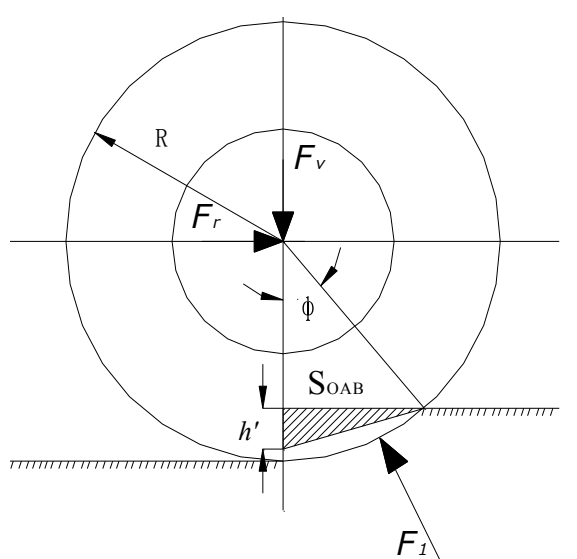

Fig. 5. Projection in vertical direction of shear failure block contacting with arc blade wedged hob. (Ozdemir. L. 1977)

The projection area in the vertical direction between the shear failure block contacting with the hob blade is simplified as a triangle, as is shown in Figure 5. The calculation formula is:

$$
S_{O A B}=\frac{1}{2} h^{\prime} \cdot R \sin \phi
$$

The formula (10) is taken into formula (9):

$F_{v 2}=F_{v 3}=\frac{h^{\prime} R \sin \phi}{2 \cos \theta} P \sin (\theta+\alpha)$

\subsubsection{Calculation of $\boldsymbol{F}_{\boldsymbol{v}}$}

In summary, the vertical cutting force $F_{v}$ can be obtained by adding component $F_{v 1}, F_{v 2}, F_{v 3}$ and so on.

When $h \leq r\left(1-\cos \theta^{\prime}\right)$,

$F_{v}=R \sin \phi \cdot \sqrt{2 r h-h^{2}} \cdot \sigma_{c}$

When $h>r\left(1-\cos \theta^{\prime}\right)$, 


$$
F_{v}=R \sin \phi \cdot r \sin \theta^{\prime} \cdot \sigma_{c}+P \frac{h^{\prime} R \sin \phi}{\cos \theta} \sin (\theta+\alpha)
$$

\subsection{Parameter analysis}

Formulas (12)-(13) indicate that the parameters influencing the vertical cutting force of the hob are $R, r, \theta, \sigma_{c}, \varphi_{b}, \alpha, \psi$. For a given stratum, $\varphi_{b}, \alpha, \psi$ is determined, the influence of hob's arc radius, angle of the blade, and the uniaxial compressive strength of the rock to the vertical cutting force is in consideration. The calculation results are shown in Figures $6-8$. When $R=216 \mathrm{~mm}, \theta=10^{\circ}, \sigma_{c}=60 \mathrm{MPa}, \varphi_{b}=$ $37^{\circ}, \alpha=13^{\circ}, \psi=20^{\circ}$. The influence of parameter $r$ on the hob vertical cutting force is shown in Figure 6 . With the increase of $r$, vertical cutting force increases accordingly, but modestly. When $R=216 \mathrm{~mm}, r=4 \mathrm{~mm}, \sigma_{c}=60 \mathrm{MPa}, \varphi_{b}=$ $37^{\circ}, \alpha=13^{\circ}, \psi=20^{\circ}$. The influence of parameter $\theta$ on the hob vertical cutting force is shown in Figure 7 . When the depth of penetration depth $h \leq r\left(1-\cos \theta^{\prime}\right), \theta$ has no effect on hob vertical cutting force; when the penetration depth $h>r\left(1-\cos \theta^{\prime}\right)$, with the increase of $\theta$, the hob vertical cutting force increases more. When $R=216 \mathrm{~mm}, r=4 \mathrm{~mm}$, $\theta=10^{\circ}, \varphi_{b}=37^{\circ}, \alpha=13^{\circ}, \psi=20^{\circ}$. The influence of parameter $\sigma_{c}$ on the hob vertical cutting force is shown in Figure 8 . With the increase of $\sigma_{c}$, the vertical cutting force increases accordingly.

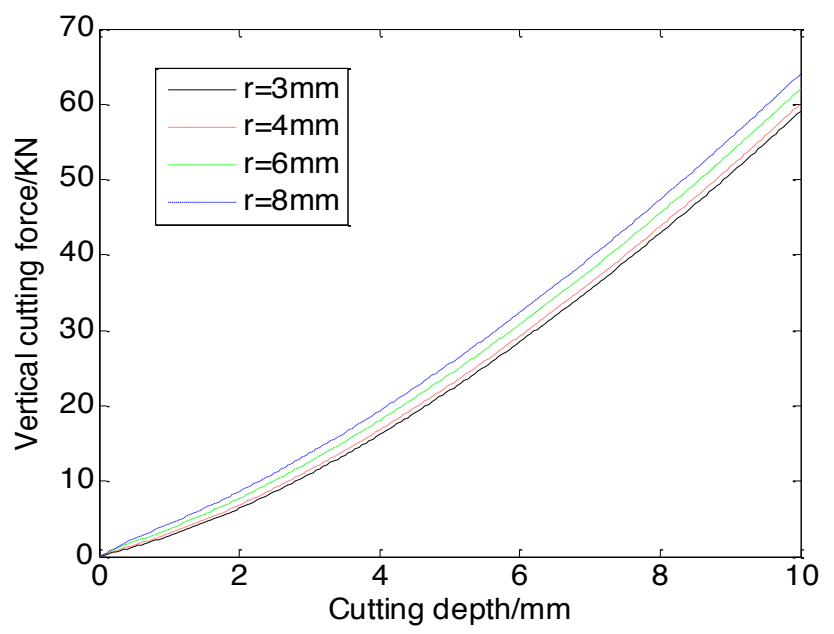

Fig. 6. Influence of $r$ versus $F_{v}$.

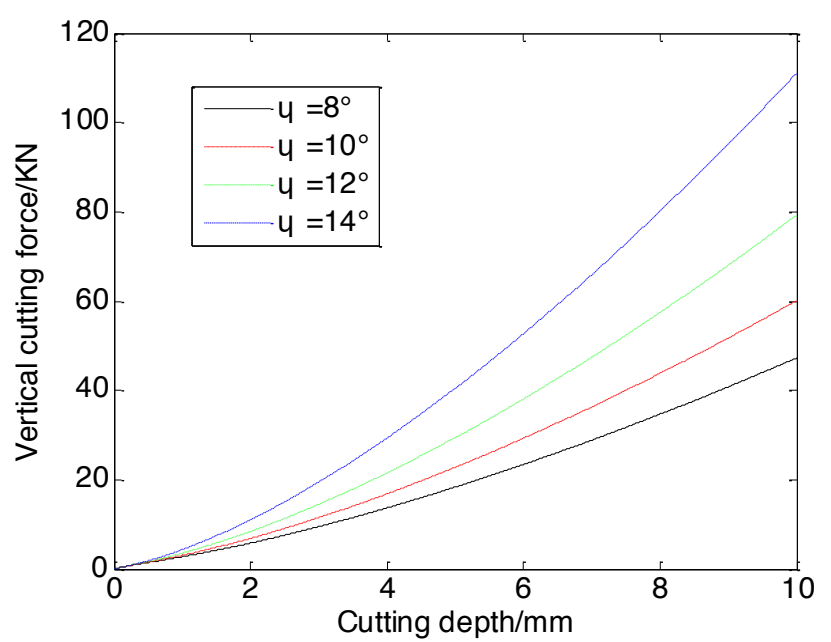

Fig. 7. Influence of $\theta$ versus $F_{v}$.

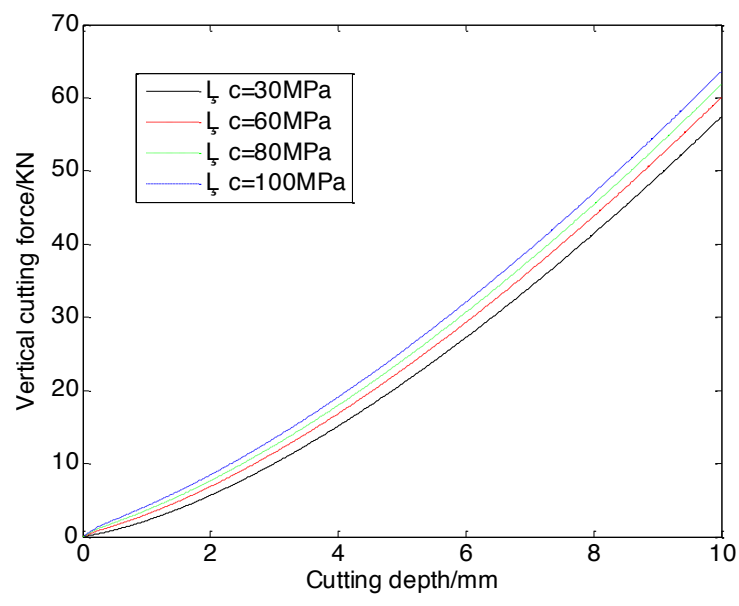

Fig. 8. Influence of $\sigma_{c}$ versus $F_{v}$.

Table 1. Mechanical parameters of in-situ rock.

\begin{tabular}{lllllll}
\hline $\begin{array}{l}\text { Density } \\
/\left(\mathbf{k g} / \mathbf{m}^{3}\right.\end{array}$ & $\begin{array}{l}\text { Compressiv } \\
\text { e strength } \\
\text { /MPa }\end{array}$ & $\begin{array}{l}\text { Shear } \\
\text { strengt } \\
\mathbf{h} / \mathbf{M P a}\end{array}$ & $\begin{array}{l}\text { Tensile } \\
\text { strengt } \\
\mathbf{h} / \mathbf{M P a}\end{array}$ & $\begin{array}{l}\text { Modulu } \\
\mathbf{s} \text { of } \\
\text { elasticit } \\
\mathbf{y} / \mathbf{G P a}\end{array}$ & $\begin{array}{l}\text { Cohesio } \\
\mathbf{n} / \mathbf{M P a}\end{array}$ & $\begin{array}{l}\text { Poisso } \\
\text { n ratio }\end{array}$ \\
\hline 2300 & 60.0 & 4.6 & 3.8 & 40 & 16.43 & 0.15 \\
\hline
\end{tabular}

Table 2. Comparison of two models under cutter spacing $\mathrm{S}=100 \mathrm{~mm}$.

\begin{tabular}{ccc}
\hline $\begin{array}{c}\text { Cutting depth } \\
/ \mathbf{m m}\end{array}$ & $\begin{array}{c}\text { Our model } \\
/ \mathbf{k N}\end{array}$ & $\begin{array}{c}\text { CSM model } \\
/ \mathbf{k N}\end{array}$ \\
\hline 0.1 & 0.35 & 1.04 \\
0.2 & 0.65 & 1.56 \\
1 & 3.16 & 3.73 \\
2 & 7.08 & 5.68 \\
4 & 16.53 & 13.18 \\
6 & 28.5 & 23.65 \\
8 & 43.42 & 36.23 \\
10 & 59.32 & 49.95 \\
\hline
\end{tabular}

Table 3. Macroparameter of cement mortar test block.

\begin{tabular}{lllllll}
$\begin{array}{l}\text { Density } \\
/(\mathbf{k g} / \mathbf{m} 3)\end{array}$ & $\begin{array}{l}\text { Elastic } \\
\text { modu } \\
\text { lus } \\
\text { /GPa }\end{array}$ & $\begin{array}{l}\text { Compress } \\
\text { ive } \\
\text { strength } \\
/ \mathbf{M P a}\end{array}$ & $\begin{array}{l}\text { Tensile } \\
\text { strength } \\
/ \mathbf{M P a}\end{array}$ & $\begin{array}{c}\text { Poisson } \\
\text { ratio }\end{array}$ & $\begin{array}{l}\text { Cohesio } \\
\mathbf{n} / \mathbf{M P a}\end{array}$ & $\begin{array}{c}\text { Internal } \\
\text { friction } \\
\text { angle } \\
/\left(^{\circ}\right)\end{array}$ \\
\hline 2560 & 1.82 & 60 & 1.8 & 0.21 & 4.12 & 35 \\
\hline
\end{tabular}

\section{Result analysis}

\subsection{Engineering data verification}

The engineering example is based on the shield tunnel engineering in Nanjing (China). The strata are mainly soft plastic silty clay, soft and hard composite strata and whole section rock. There exists Cretaceous Pukou formation sandstone, argillaceous sandstone, mudstone and sandy mudstone locally along the bedrock, mainly soft rock. The mechanical parameters of the stratum are shown in Table 1.

The cutter head structure of the shield machine is a combined spoke-type cutter head, it includes a set of 4 double-blade hobs with spacing $90 \mathrm{~mm}, 21$ single bladed hobs with spacing $100 \mathrm{~mm}, 11$ edged hob with diameter of $17^{\prime \prime}$. The disc cutter shape parameters are $\mathrm{D}=2 \mathrm{R}=432 \mathrm{~mm}$, $\mathrm{r}=4 \mathrm{~mm}, 2 \theta=20^{\circ}$. The cutter structure is shown in Figure 9 (a). The in-situ engineering construction figure is shown in Figure 9 (b). To facilitate the comparison of the model and actual engineering data, according to the parameters of rock, the friction coefficient of sandstone is usually assumed as 0.75 , then $\varphi_{b}=\arctan 0.75=37^{\circ}$. The natural fracture angle of 
sandstone is $140^{\circ}$, then $\psi=\frac{180^{\circ}-140^{\circ}}{2}=20^{\circ}$. According to the friction factor of metal and stone, the friction coefficient of hob and rock is 0.23 , then the friction angle is $\alpha=\arctan 0.23=13^{\circ}$. The critical angle of rock shear failure can be obtained using the parameters $\theta^{\prime}=\pi / 2-\left(\varphi_{b}+\alpha+\psi\right)=20^{\circ}$, and the critical cutting depth of hob broken rock is $h=r\left(1-\cos \theta^{\prime}\right)=0.24 \mathrm{~mm}$. When the penetration depth $h \leq r\left(1-\cos \theta^{\prime}\right) \quad, F_{v}=R \sin \phi \cdot \sqrt{2 r h-h^{2}} \cdot \sigma_{c} ;$ when the penetration depth $h>r\left(1-\cos \theta^{\prime}\right)$, $F_{v}=R \sin \phi \cdot r \sin \theta^{\prime} \cdot \sigma_{c}+P \frac{h^{\prime} R \sin \phi}{\cos \theta} \sin (\theta+\alpha)$. The CSM model $F_{v}=D^{\frac{1}{2}} h^{\frac{3}{2}}\left[\frac{4}{3} \sigma_{c}+2 \tau\left(\frac{S}{h}-2 \tan \frac{\alpha}{2}\right)\right] \tan \frac{\alpha}{2}$

(Ozdemir L. et al. 1977). The calculation results of the CSM model and this paper's model under different cutting depths are as shown in Table 2.

(a) Cutter head structure.
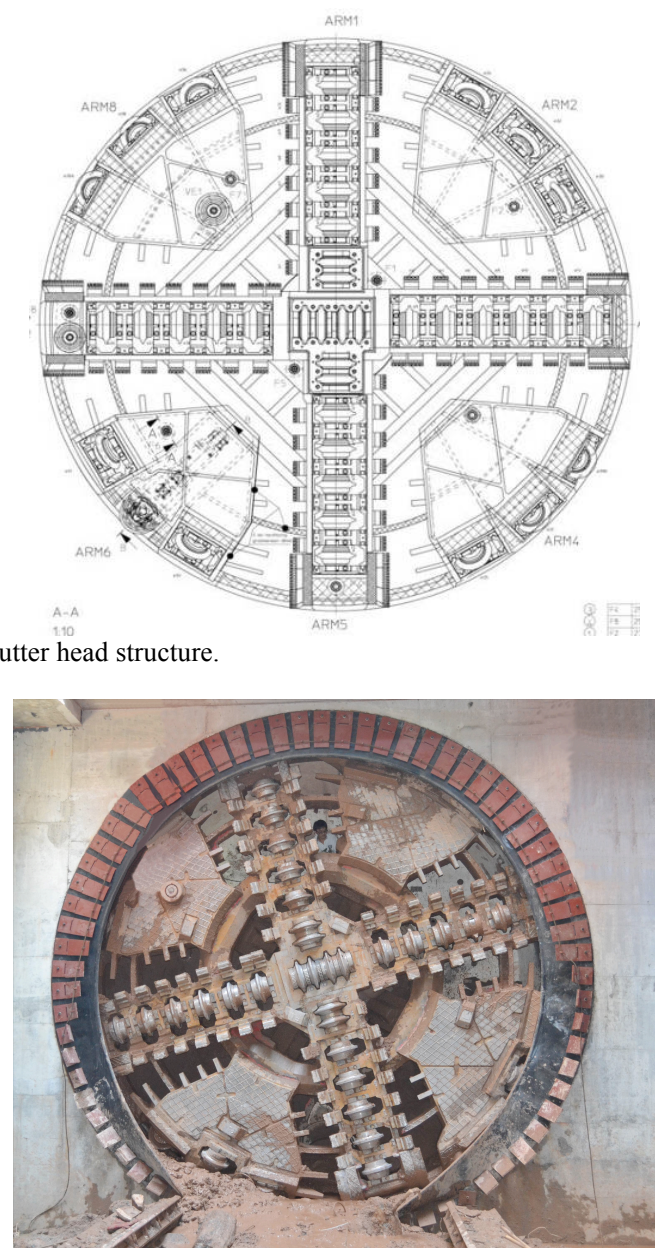

(b) The in-situ engineering construction figure.

Fig. 9. TBM hob structure diagram.

The calculation results of this paper's model and the CSM results are shown in Table 2 and Figure 10. When the hob cutting depth is less than the critical point, this paper's model only considered the extrusion influence, so the calculation results are less than CSM model. However, with the increase in hob cutting depth, our model calculation results are greater than the CSM results, mainly due to $F_{v 2}$ and $F_{v 3}$ are taken into consideration. When the working depth of the hob intrusion in rocks is $8 \mathrm{~mm}$, the vertical cutting force of this paper's model is $F_{v}=43.42 \mathrm{kN}$.
According to the measured data, an average thrust of the shield machine in the process of excavating is $1900 \mathrm{kN}$, and there are 40 hobs in the cutter disk. The average vertical thrust of each hob is about $47.5 \mathrm{kN}$.

The prediction model's results of rock breaking in this paper are closer to the measured results than the CSM results. The engineering example confirms that our model is feasible and practical.

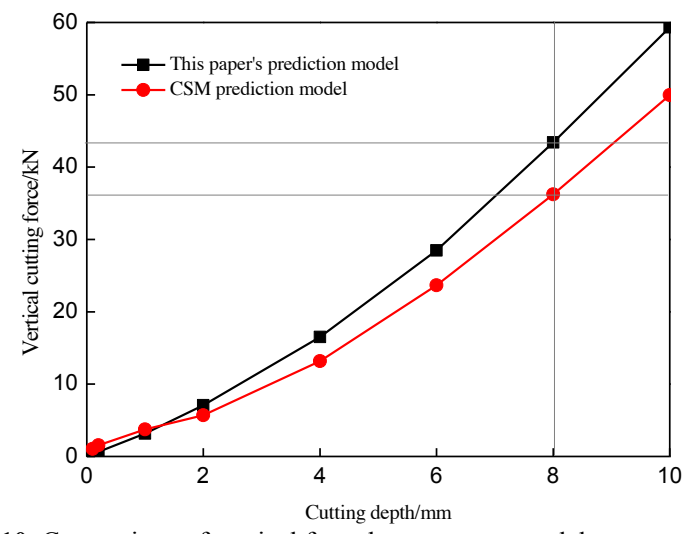

Fig. 10. Comparison of vertical force between two models.

\subsection{Model test and result analysis}

Our laboratory develops a simulation test system of TBM hob breaking rock. The macroscopic failure form of the rock and tunnel face shape under the action of the hob is analyzed, different cutter spacings affecting the rock-breaking efficiency are studied by adjusting the spacing of the hobs. The length of the shield is $2 \mathrm{~m}$, outside diameter of shield model is $413 \mathrm{~mm}$, and the shield tail is mounted by hydraulic jack to provide power for excavation along the axial movement of the cutter, hydraulic jacks is connected to the hydraulic loading system, the size of vertical force as well as the cutter speed is controlled by hydraulic loading system, the cutter speed is controlled within $10-60 \mathrm{~mm} / \mathrm{min}$. The motor driving device is installed in the rear of the cutter to provide power for the cutter rotation. The cutter speed is controlled within $1-20 \mathrm{r} / \mathrm{min}$.

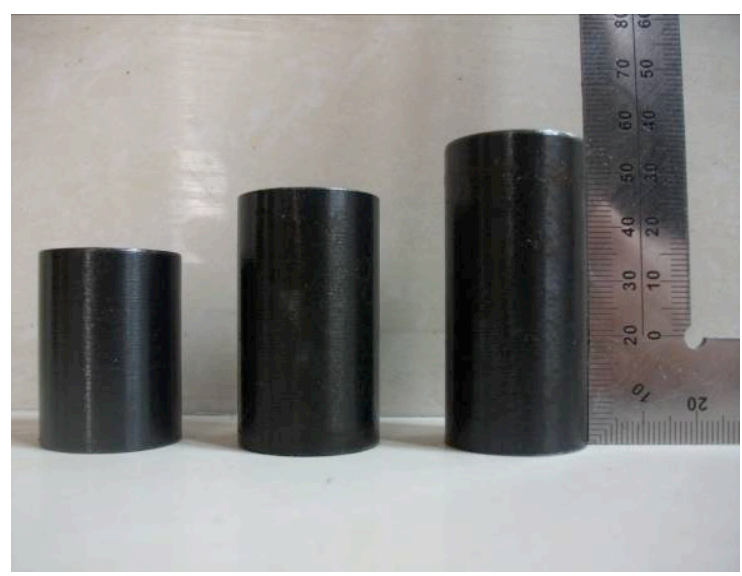

Fig. 11. Different size sleeves.

To simulate the cutting experiment, the cutter diameter is $400 \mathrm{~mm}$, the cutter head is consist of center fish cutter, rockbreaking disc hob, and edged scraper. There are four bearings radiate from the center of the cutter, two hobs are installed on each bearing, the hob spacing is adjusted by different sizes of sleeve, the size of sleeve is shown in Figure 11 , hob diameter is $58 \mathrm{~mm}$. Three kinds of different 
spacing (i.e., $50 \mathrm{~mm}, 60 \mathrm{~mm}, 70 \mathrm{~mm}$ ) are used in the cutting experiment, as is shown in Figure $12(\mathrm{a}-\mathrm{c})$.

Cement mortar is used to simulate rock in accordance with maintenance period, the ratio is water: cement: sand: gypsum $=0.8: 1: 1: 3$. The mechanical indexes of the cement mortar are shown in Table 3 . The cutter ring material parameters are: density $=7900 \mathrm{~kg} / \mathrm{m}^{3}$, elastic modulus $\mathrm{E}=$ $206 \mathrm{GPa}$, and poisson ratio $\mu=0.3$.

The rock-breaking efficiency of three kinds of hob spacing arrangement is shown in Figures 13-15. It can be seen that at the beginning of the invasion period, the hobs roll and press rocks, and a large amount of rock powder is ejected from the wedge surface of the hob. Rock damage mainly occurs just below the blade of the hob, rocks in the contact point are broken, crushed rocks are cut off by the rotating cutter, as shown in Figure 13-15 (a). With the increasing of hob penetration depth, axial cracks below the blade continue to expand in depth, the dense extrusion block is formed in the blade contacting with rock, dense extrusion block passes pressure, a series of lateral cracks are gradually formed, and rock blocks are broken on both sides of the blade and fall down by the action of the hobs, as shown in Figure 13-15 (b). When the cutter moves forward, lateral cracks fully develop on both sides of the blade under dense extrusion block and lateral cracks between the adjacent hobs gradually converge, resulting in rock shear failure and rock mass falling, as shown in Figure 13-15 (c).

When the hob spacing is $70 \mathrm{~mm}$, the rock beneath the hob blade gradually experiences extrusion shear failure with

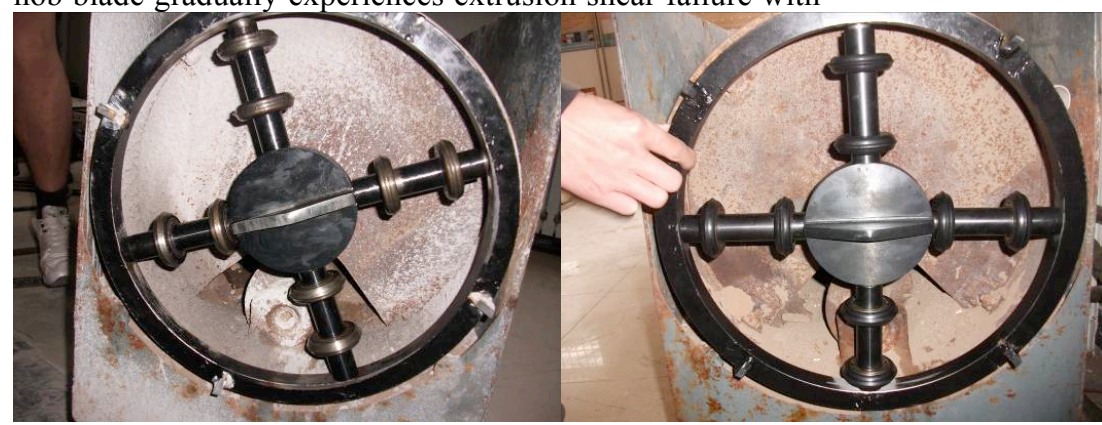

(a) $50 \mathrm{~mm}$ (b) $60 \mathrm{~mm}$ the increasing cutting depth, but the expansion of the lateral cracks on both sides of the blade is not sufficient. Therefore, the lateral cracks between adjacent hobs has not formed the intersection, so this part of rocks fails to break from the mother rock. The rock ridge is formed after rock-breaking, and rock-breaking efficiency is not optimal, as shown in Figure 13 (c).

The lateral cracks of hob spacing $60 \mathrm{~mm}$ compared that of hob spacing $70 \mathrm{~mm}$ show more development, but still fail to create intersection between lateral cracks. When the invasion depth reaches $10 \mathrm{~mm}$, the narrow rock ridges still appear in the middle of adjacent hobs, and the rock-breaking efficiency is not yet optimal, as shown in Figure 14 (c). When the hob spacing is $50 \mathrm{~mm}$, intermediate main and lateral cracks are fully developed in the process of rock breaking, and intersection between the lateral cracks and adjacent hobs are completed. This part of the rock can be completely separated from the mother rock, and the rock breaking efficiency is the best, as shown in Figure 15 (c).

It can be seen from the figure of rock breaking traces, the rock-breaking mechanism of disc cutter is the hob shearing and extrusion of rocks from the mother rock, and finally a series of concentric grooves are formed. The larger the hob spacing is, the more regular the concentric circle is formed. The smaller the hob spacing is, the more damage concentric edge occurs, which also indicates that suitable hob spacing can achieve better rock-breaking efficiency.

Fig. 12. Cutters in different hob spacing.

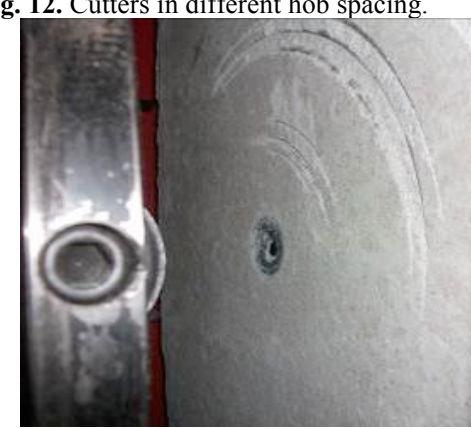

(a) $2 \mathrm{~mm}$

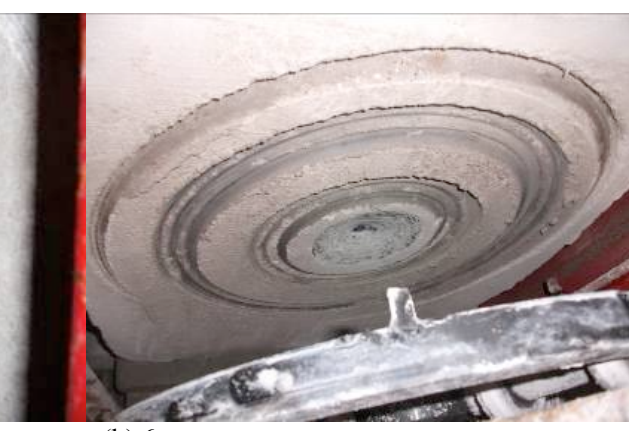

(b) $6 \mathrm{~mm}$

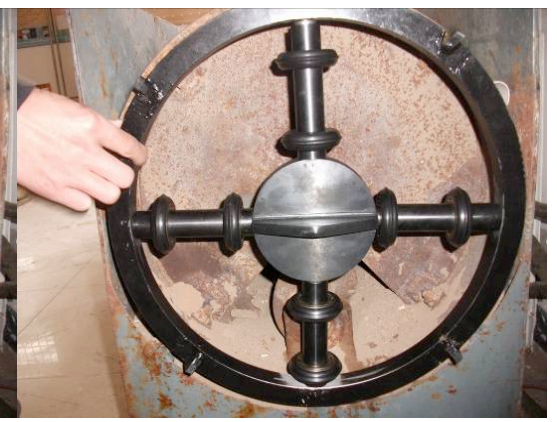

(c) $70 \mathrm{~mm}$

Fig. 13. Rock-breaking efficiency of cutters under hob spacing of $70 \mathrm{~mm}$.

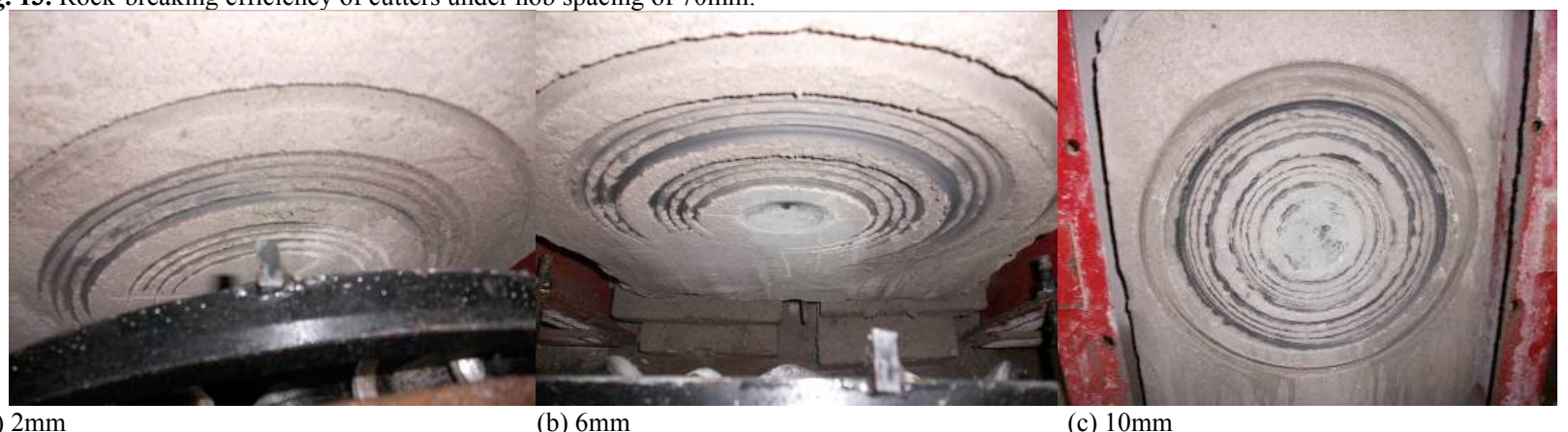

(a) $2 \mathrm{~mm}$

(b) $6 \mathrm{~mm}$

(c) $10 \mathrm{~mm}$

Fig. 14. Rock-breaking efficiency of cutters under hob spacing of $60 \mathrm{~mm}$. 


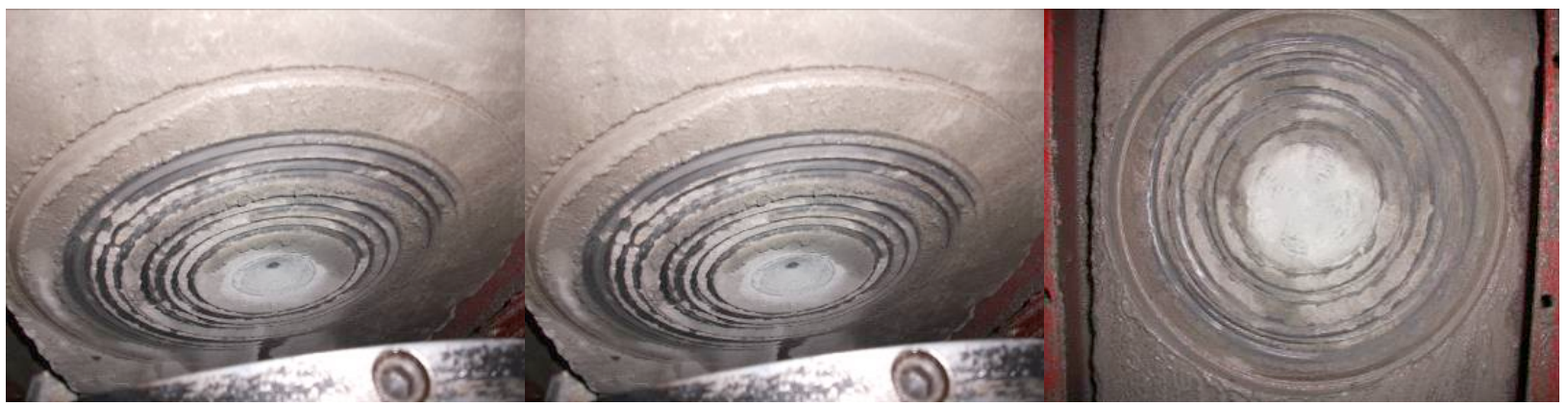

(a) $2 \mathrm{~mm}$

(b) $6 \mathrm{~mm}$

(c) $10 \mathrm{~mm}$

Fig. 15. Rock-breaking efficiency of cutters under hob spacing of $50 \mathrm{~mm}$.

\section{Conclusion}

Based on the stress analysis of rock-breaking by arc blade wedged hob and the research on model tests, the following conclusions can be drawn:

(1) Rock fragmentation of arc blade wedged hob is the result of combination of extrusion and shear breakage. The vertical cutting force prediction model is improved based on stress analysis of the extrusion and shear failure block.

(2) The engineering example confirms that our model is feasible and practical. The prediction model's results are closer to the measured results than the results of traditional linear cutting model(CSM). It is of great significance to design the arc blade wedge hob.

(3) The spoke type cutter head model similar to the actual TBM cutter head is designed, the distance between the hobs can be adjusted by changing the sleeve size, rockbreaking efficiency of different hob spacing is studied, there exists the optimal hob spacing to get the highest rockbreaking rate. It is necessary to adjust the spacing to enhance the efficiency of rock fragmentation in rock strata.

\section{Acknowledgements}

The was supported by National Natural Science Foundation of China (No.51274209, 41472259, 51304215); State Key Program of National Natural Science of China (coal joint fund No.U1261212); National Key Technology Support Program (No.2012BAK24B0201).

\section{References}

1. Roxborough, F. F., and Phillips, H. R., "Rock excavation by disc cutter", International Journal of Rock Mechanics and Mining Sciences, 12(12), 1975, pp. 361-366.

2. Ozdemir, L., Miller, R., and Wang F. D., "Mechanical tunnel boring prediction and machine design. Annual report", International Journal of Rock Mechanics and Mining Sciences, 15(5), 1978, pp: A105.

3. Gong, Q. M., and Zhao, J., "Influence of rock brittleness on TBM penetration rate in Singapore granite", Tunnelling and Underground Space Technology, 22(3), 2007, pp. 317-324.

4. Gong, Q. M., Zhao, J., and Jiang, Y. S., "In situ TBM penetration tests and rock mass boreability analysis in hard rock tunnels", Tunnelling and Underground Space Technology, 22(3), 2007, pp. 303-316.

5. Gong, Q. M., and Zhao, J., "Development of a rock mass characteristics model for TBM penetration rate prediction", International Journal of Rock Mechanics and Mining Sciences, 46(1), 2009, pp. 8-18.

6. Gong, Q. M., Jiao, Y. Y., and Zhao, J., "Numerical modelling of the effects of joint spacing on rock fragmentation by TBM cutters", Tunnelling and Underground Space Technology, 21(1), 2006, pp. 46-55.

7. Hassanpour, J., Rostami, J., and Zhao, J., "A new hard rock TBM performance prediction model for project planning”, Tunnelling and Underground Space Technology, 26(5), 2011, pp. 595-603.

8. Sapigni, M., Berti, M., Bethaz, E., Busillo, A., and Cardone, G., "TBM performance estimation using rock mass classifications", International Journal of Rock Mechanics and Mining Sciences, 39(6), 2002, pp. 771-788.
9. Ribacchi, R., and Fazio, A. L., "Influence of rock mass parameters on the performance of a TBM in a Gneissic formation (Varzo Tunnel)", Rock Mechanics and Rock Engineering, 38 (2), 2005, pp. 105-127.

10. Hamidi, J. K., Shahriar, K., Rezai, B., and Rostami, J., "Performance prediction of hard rock TBM using Rock Mass Rating (RMR) system", Tunnelling and Underground Space Technology, 25(4), 2010, pp.333-345.

11. Song, K. Z., Yuan, D. J. and Wang, M. S., "Study review on the interaction between disk cutter and rock", Journal of Railway Engineering Society, 22(6), 2005, pp. 66-69.

12. Yagiz, S., "Utilizing rock mass properties for predicting TBM performance in hard rock condition", Tunnelling and Underground Space Technology, 23 (3), 2008, pp. 326-339.

13. Entacher, M., Schuller, E., and Galler, R., "Rock failure and crack propagation beneath disc cutters", Rock Mechanics and Rock Engineering, 48(4), 2015, pp. 1559-1572.

14. Marji, M., Nasab, H. H., and Morshedi, A. H., "Numerical modeling of crack propagation in rocks under TBM disc cutters", Journal of Mechanics of Materials and Structures, 4(3), 2009, pp. 605-627.

15. Cho, J. W., Jeon, S., Yu, S. H., and Chang, S. H., "Optimum spacing of TBM disc cutters: A numerical simulation using the three-dimensional dynamic fracturing method", Tunnelling and Underground Space Technology, 25(3), 2010, pp. 230-244.

16. Ma, H. S., Yin, L. J., and Ji, H. G., "Numerical study of the effect of confining stress on rock fragmentation by TBM cutters", International Journal of Rock Mechanics and Mining Sciences, 48(6), 2011, pp. 1021-1033.

17. Acaroglu, O., "Prediction of thrust and torque requirements of TBMs with fuzzy logic models", Tunnelling and Underground Space Technology, 26(2), 2011, pp. 267-275. 